\title{
Análise do potencial eólico Brasileiro: estudo de caso in loco da construção do parque eólico em Santa Luzia - PB
}

Dryelle Tuanne de Souza

dryellesouza.engcivil@gmail.com

Sérgio Thales Amaro Alves sergioamaro.engcivil@hotmail.com UNIPÊ, João Pessoa, Paraiba, Brasil

Adriana de Souza Nascimento adriananascimento.eng@gmail.com UFCG - Campina Grande, Paraíba, Brasil

Antônio da Silva Sobrinho Júnior sobrinhojr@hotmail.com UNIPÊ, João Pessoa, Paraíba, Brasil

Miguel Otávio Barreto Campelo de Melo

miguelmelo@asces.edu.br UNITA, Caruaru, Pernambuco, Brasil

\author{
RESUMO
}

Buscar fontes de energia limpa e inesgotáveis vem se tornando cada vez mais comum e necessário. O Brasil foi pioneiro entre os países da América Latina, durante a década de 90, aderindo à tecnologia de energia eólica ao instalar o primeiro aerogerador. Com o avanço dessa tecnologia e as excelentes condições encontradas por pesquisadores e investidores, principalmente na região Nordeste, a criação de parques eólicos cresceu consideravelmente ao longo dos anos, com potencial para crescer cada vez mais, enaltecendo o setor da construção civil. O objetivo deste artigo foi analisar o potencial eólico brasileiro, abordando aspectos relevantes, contribuições sociais, ambientais e econômicas, vantagens deste tipo de produção para a região, tendo a vivência in loco, na análise da construção de um Parque eólico situado em Santa Luzia -PB. A cidade do estudo é reconhecida pelo seu alto índice de ventos, passando a ser conhecida como "corredor de vento". A pesquisa caracteriza-se como bibliográfica, exploratória e documental, tendo o estudo de caso como metodologia. Conclui-se diversos benefícios na utilização deste tipo de energia, ambientais, sociais e econômicos, e que, as inovações no setor de energia eólica brasileiro, proporcionam, principalmente no Nordeste Brasileiro, a complementaridade eólica-hídrica colaborando para aumento da segurança energética do sistema elétrico brasileiro nos períodos do ano de maior e menor disponibilidade de água nos reservatórios das usinas hidroelétricas.
\end{abstract}

PALAVRAS-CHAVE: Energia Eólica. Parque Eólico Santa Luzia. Construção de Parques Eólicos. Energias Renováveis. 


\section{INTRODUÇÃO}

A questão energética vem sendo um tema crescentemente discutido nos últimos anos. $\mathrm{O}$ avanço exacerbado na demanda de energia mundial em razão da melhoria do padrão de vida traz inquietações com relação a alguns aspectos de mera importância tanto para a política quanto para o planejamento energético de diversos países. Desde o princípio, o ser humano extrai recursos naturais necessários para mitigar as suas necessidades ou realizar suas atividades, considerando esses recursos como fontes infinitas.

Tratando-se de qualidade de vida de uma sociedade, boa parte relacionase às tarefas desempenhadas pelo seu consumo de energia elétrica. Com isso, o desenvolvimento da demanda energética no mundo conduz a inúmeras preocupações, dentre essas, devemos cogitar os custos para atender a toda essa demanda, em tempos de dificuldade econômica em que a população necessita e preza por uma vida cômoda e saudável, faz-se considerável a adoção de fontes energéticas renováveis e limpas.

Energia renovável é uma energia derivada de processos naturais que são ou podem ser constantemente reabastecidos e incluem energia solar, eólica, biomassa, geotérmica, hidrelétrica, energia mare motriz e biocombustíveis (SCHOLTEN e BOSMAN, 2013). Tais fontes são reabastecidas por processos naturais a um ritmo igual ou superior à sua utilização (GREENPEACE, 2013).

Segundo EPE (2017), a participação de fontes renováveis na Matriz Energética Brasileira manteve-se entre as mais elevadas do mundo. No cenário atual, o Brasil dispara na liderança de uso de fontes renováveis para geração de energia elétrica, ocupando uma posição bastante considerável no ranking, conforme é possível observar na Figura 1. O Ministério de Minas e Energia, em dados publicados no boletim de capacidade instalada de geração elétrica em 2016, afirma que a capacidade instalada de geração de energia no Brasil chegou a 150,4 GW em 2016, aumento de 9,5 GW em relação a 2015. Do total da expansão, $90 \%$ foram de renováveis, que continuam em destaque no País.

Figura 1 - Participação de renováveis na matriz energética

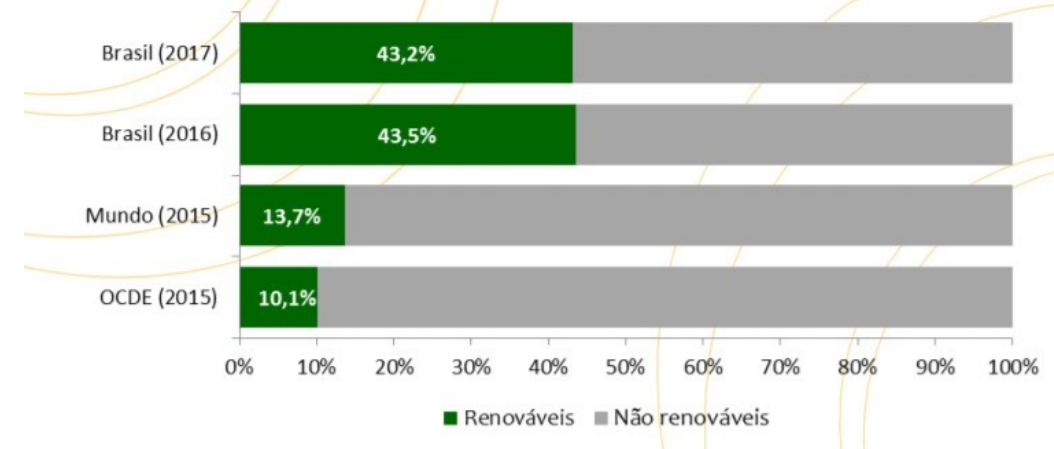

Fonte: EPE, 2017

No Brasil, o campo de energia eólica vem crescendo consideravelmente, levando o país a uma notável posição de liderança no ranking mundial de potencialização da capacidade eólica desenvolvida e aprimorada constantemente, afinal, o país dispõe de condições muito favoráveis à implantação deste tipo de energia, já que em suas regiões venta frequentemente e, além disso, prioriza por grandes investimentos que vem tornando o país referência mundial. 
Em 2017, segundo o Boletim Anual de Energia Eólica, foram instaladas 79 novas usinas eólicas, num total de 2.027,00 MW. Os estados com maior destaque na implantação desses novos empreendimentos foram Piauí e Bahia, que juntos correspondem a pouco mais da metade de toda instalação (ABEEÓLICA, 2017).

A região Nordeste principalmente, está despertando o interesse de empresas para investimentos de instalação, devido ao seu excelente potencial, se comparado as outras regiões do país. Logo, devido à esse crescimento, busca-se neste artigo analisar o potencial eólico brasileiro enfatizando quais aspectos relevantes, e consequentemente, as vantagens deste tipo de produção para a região de implantação dos parques, tendo como vivência in loco a análise da construção de um Parque eólico em Santa Luzia - PB.

\section{FUNDAMENTAÇÃO TEÓRICA}

\section{PANORAMA DA ENERGIA EÓLICA E POTENCIAL EÓLICO BRASILEIRO}

A energia eólica além de ser uma fonte com baixíssimo impacto de implantação, não emite $\mathrm{CO} 2$ em sua operação, substituindo, portanto, outras fontes de geração de energia elétrica com emissão (ABEEÓLICA, 2017). De acordo com o Boletim anual de Energia Eólica de 2017, a energia produzida pelos ventos possui contribuições além da dimensão econômica no qual se pode observar na tabela 1.

Tabela 1 - Contribuição Sócio Ambiental da Energia Eólica

Renovável, não polui, possui baixo impacto ambiental e contribui
para que o Brasil cumpra seus objetivos no Acordo do Clima.
Parques eólicos não emitem CO2.
Um dos melhores custo-benefício na tarifa de energia.
Gera renda e melhoria de vida para proprietários de terra com
arrendamento para colocação das torres.
Permite que o proprietário da terra siga com plantações ou criação
de animais.
Geração de emprego e capacitação de mão de obra local.

Fonte: Autoria própria, adaptado de ABEEÓLICA (2017).

A produção de eletricidade a partir da fonte eólica alcançou $33.489 \mathrm{GWh}$ em 2016, equivalente a um aumento de $54,9 \%$ em relação ao ano anterior, quando se atingiu $21.626 \mathrm{GWh}$. Em 2016, a potência instalada para geração eólica no país expandiu 33\%. Segundo o Banco de Informações da Geração (BIG), da Agência Nacional de Energia Elétrica (ANEEL), o parque eólico nacional cresceu 2.491MW, alcançando 10.124MW ao final de 2016 (EPE, 2017). As usinas eólicas e solares foram responsáveis pelos $26,3 \%$ restantes de aumento do grid nacional (EPE, 2017). 
Figura 2 - Participação das Fontes na Capacidade Instalada

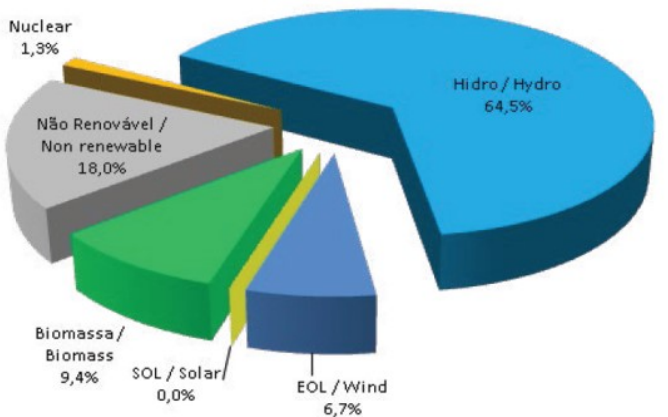

Fonte: EPE, 2017.

Mesmo o país possuindo um bom potencial para geração de energias alternativas à hidrelétrica, sendo estas também de caráter renováveis, o aproveitamento desses recursos para geração de energia é muito baixo, onde, segundo o MME (2018), na oferta de energia interna no ano de 2016 somente 6,6 $\%$ foram responsáveis pela energia eólica, e 0,01 \% pela energia solar.

Importante ressaltar que o Brasil foi o primeiro país da América Latina a instalar um aerogerador, por volta de meados da década de 90 . Durante a década seguinte, pouco houve avanço na consolidação da energia eólica como alternativa de geração de energia elétrica no país, tanto por questões de altos investimentos, quanto pela falta de políticas de incentivo voltados para esta prática (SIMAS, 2013).

No ano de 2001, foi registrado o primeiro Atlas Eólico Brasileiro, onde foi obtido que as principais regiões para o aproveitamento do recurso eólico são Nordeste, Sudeste e Sul, que juntos correspondem a cerca de $90 \%$ de todo o potencial eólico brasileiro. Atualmente, conforme afirma ABEEOLICA (2017), os cinco estados com maior geração no período de 2017, foram Rio Grande do Norte (13,24 TWh), Bahia (7,79 TWh), Rio Grande do Sul (5,58 TWh), Ceará (5,10 TWh) e Piauí (4,59 TWh), conforme observa-se na Figura 3.

Figura 3 - Geração e representatividade da fonte eólica

\begin{tabular}{|c|c|c|c|c|c|}
\hline Reglão & $\begin{array}{l}\text { Geração } \\
\text { (TWh) }\end{array}$ & $\begin{array}{l}\text { Represen- } \\
\text { tatlvidade }\end{array}$ & $\begin{array}{l}\text { Geração } \\
\text { (TWh) }\end{array}$ & $\begin{array}{l}\text { Represen- } \\
\text { tatlvidade }\end{array}$ & $\begin{array}{c}\% \text { de } \\
\text { cresclmento }\end{array}$ \\
\hline Sudeste & 0,07 & $0,2 \%$ & 0,08 & $0,2 \%$ & $13 \%$ \\
\hline Sul & 4,83 & $15,1 \%$ & 5,84 & $14,4 \%$ & $21 \%$ \\
\hline Nordeste & 21,17 & $84,7 \%$ & 33,99 & $84,0 \%$ & $25 \%$ \\
\hline Norte & - & -- & 0,55 & $1,4 \%$ & $--\%$ \\
\hline Total & 32,07 & $100 \%$ & 40,46 & $100 \%$ & $26,2 \%$ \\
\hline
\end{tabular}

Fonte: ABEEÓLICA, 2017.

Segundo o Boletim Anual de Geração de Energia Eólica (2017), em 2017 foram instaladas 79 novas usinas eólicas no Brasil, num total de 2.027,00 MW, totalizando 530 usinas eólicas instaladas, gerando a capacidade de $12,77 \mathrm{GW}$, o que representou um crescimento de $18,87 \%$ de potência, reduzindo 23.000 .000 T/ano de $\mathrm{CO} 2$. 
Figura 4- Geração por Estado em 2017 (MW médio)

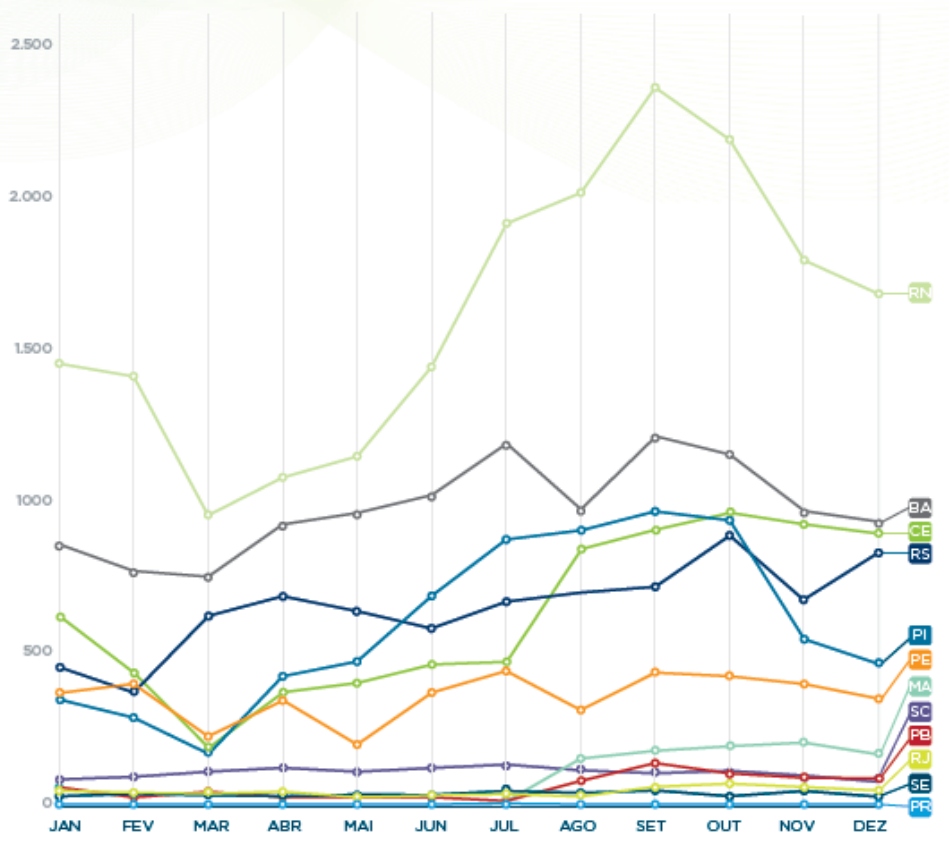

Fonte: ABEEÓLICA, 2017

No total, foram gerados 42,25 TWh de energia eólica ao longo de 2017, sendo $62,52 \%$ da geração produzida no período de safra dos ventos, que vai de julho a dezembro. Em termos de representatividade e abastecimento, a geração verificada pela fonte eólica foi responsável por $7,44 \%$ na média de toda a geração injetada no SIN - Sistema Interligado Nacional ${ }^{1}$.

A capacidade instalada de $12,77 \mathrm{GW}$ é composta por $12,41 \mathrm{GW}$ de parques em operação comercial $(97,23 \%), 0,26 \mathrm{GW}$ de operação em teste (2\%) e $0,098 \mathrm{GW}$ de parques aptos a operar (0,77\%).

Figura 5 - Evolução da capacidade instalada 2017 (MW)

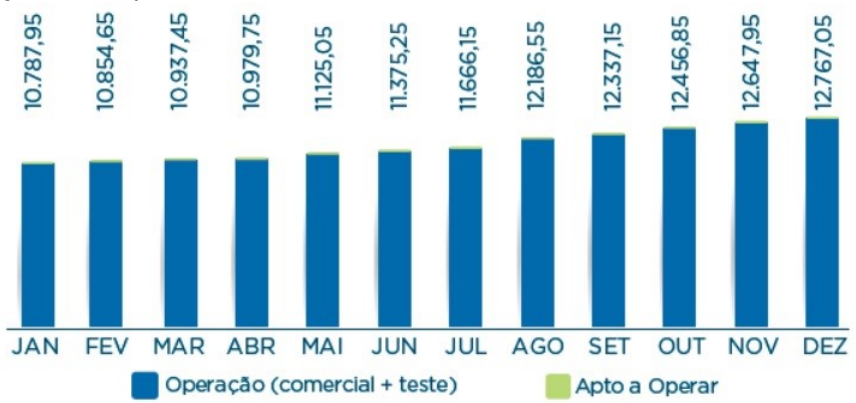

Fonte: ANEEL/ABEEÓLICA, 2017.

Em relação a situação dos parques eólicos, segundo o relatório mensal de dezembro de 2018 , os instalados são subdivididos em três categorias: aptos a operar, operando em teste e operando comercialmente. A capacidade instalada no início de dezembro de 2018 foi 14,49 GW (ABEEÓLICA, 2018).

$A$ região do Brasil com o maior potencial de produção de energia elétrica a

${ }^{1}$ O SIN é composto de quatro subsistemas: Nordeste, Norte, Sudeste/Centro-Oeste e Sul. A divisão destes não é a mesma que a estabelecida geograficamente. No caso das eólicas, o que estiver representado no subsistema Norte é o que está localizado no Maranhão. 
partir dos ventos é o Nordeste, gerando 7,5GW dos projetos eólicos em implantação e os projetados com construção. Segundo a Abeeólica (2018), o mês de dezembro de 2018 foi iniciado com uma capacidade eólica instalada de 14,49 $\mathrm{GW}$, sendo assim, a participação dessa fonte na matriz alcançou $9 \%$.

\section{SUSTENTABILIDADE E O SETOR DA CONSTRUÇÃO CIVIL}

Em busca de um planeta mais sustentável, onde os recursos naturais são utilizados de maneira mais consciente e eficiente, diminuindo assim os danos causados ao meio ambiente, medidas foram impostas pelos países em todo planeta, visto isso, em 2015 foi criado um acordo denominado Acordo de Paris, onde diversos países do mundo se reuniram com uma mesma finalidade, a qual era de se adotar metas e firmar compromissos buscando minimizar os impactos negativos gerados ao meio ambiente ao longo dos anos (BORBA, 2018).

Durante esse acordo o Brasil se comprometeu a reduzir as emissões de gases de efeito estufa em $37 \%$ no ano de 2025 , e chegando a $43 \%$ no ano de 2030 , possuindo como referência para essa redução, a quantidade de gases emitidos no ano de 2005 (CBIC, 2017).

A Câmara Brasileira da indústria da construção - CBIC (2017), aborda propostas para o desenvolvimento sustentável da cadeia produtiva da Construção Brasileira, trazendo como desafios uma construção civil com mais inovações tecnológicas, desejando construções mais rápidas e eficientes, com maior durabilidade, menor consumo de água e energia, utilizando materiais sustentáveis, objetivos estes obtidos através de gestão.

Para conseguir atingir esta meta, o Brasil pretende adotar medidas em vários segmentos da economia brasileira, dentre eles os setores: Biomassa sustentável, ampliando a utilização biocombustíveis como o biodiesel, biogás e o etanol. No setor florestal, adotando medidas contra o desmatamento das florestas e mudança do uso da terra. No setor agrícola, buscar utilizar tecnologia e um manejo em que cause menos danos ao meio ambiente. Para o setor de transportes, incentivar o uso, e o desenvolvimento de transportes mais sustentáveis, entre diversas outras medidas (MME, 2018).

Em relação ao setor energético Brasileiro, foram firmadas ações previstas na Tabela a seguir, com o prazo estabelecido até o ano de 2030 para obtenção desses resultados, conforme tabela 2 .

Tabela 2 - Ações para o setor de energia previstas para até 2030

\begin{tabular}{cc}
$\begin{array}{c}\text { Participação das energias renováveis na } \\
\text { matriz energética }\end{array}$ & Atingir $45 \%$ \\
$\begin{array}{c}\text { Expandir do uso de fontes renováveis na } \\
\text { matriz total de energia }\end{array}$ & Participação de $28 \%$ a $33 \%$ \\
$\begin{array}{c}\text { Expandir a parcela de energias renováveis } \\
\text { para o fornecimento de energia elétrica } \\
\text { no uso doméstico }\end{array}$ & Ao menos $23 \%$ \\
Ganho de Eficiência no setor elétrico & Atingir $10 \%$ \\
\hline
\end{tabular}
Fonte: Adaptado de CBIC, (2017)

Apontada pelo Conselho Internacional da Construção como um dos setores de atividades humanas que mais consome recursos naturais e utiliza energia de forma intensiva, a indústria da construção tem o dever de pautar o 
desenvolvimento sustentável e transformar a realidade na forma de viver das populações (SEBRAE, 2018).

Segundo Sebrae (2018), "não há dúvidas de que todos os setores econômicos - desde o setor produtivo primário até a indústria criativa - são unânimes em defender a produção de bens e prestação de serviços eficientes, com o menor impacto ambiental e melhor otimização dos recursos naturais".

Adicionado a esse cenário, desde 17 de abril de 2012, a ANEEL através da Resolução 482, pela primeira vez no país, adotou a possibilidade para o acesso de microgeração e minigeração distribuídas interligadas aos sistemas de distribuição de energia elétrica (grid elétrico) e ao sistema de compensação de energia elétrica, para energias de fontes renováveis - Geração Distribuída.

Essa política tende a estimular os pequenos geradores e está trazendo diversos benefícios para o panorama do setor elétrico brasileiro, pois permite o acesso à geração em todos os níveis da cadeia produtiva do setor elétrico (distribuição, subtransmissão e transmissão), podendo ser um impulsionador para a geração eólica no país (ANEEL, 2018).

Segundo a Agência Nacional de Energia Elétrica - ANEEL (2018), os estímulos à geração distribuída se justificam pelos potenciais benefícios que tal modalidade pode proporcionar ao sistema elétrico. Entre eles, estão o adiamento de investimentos em expansão dos sistemas de transmissão e distribuição, o baixo impacto ambiental, a redução no carregamento das redes, a minimização das perdas e a diversificação da matriz energética.

\section{BALANÇO ENERGÉTICO NACIONAL VISANDO À ENERGIA EÓLICA}

Segundo EPE (2017), a produção de eletricidade a partir da fonte eólica alcançou $33.489 \mathrm{GWh}$ em 2016, equivalente a um aumento de 54,9\% em relação ao ano anterior, quando se atingiu $21.626 \mathrm{GWh}$. Em 2016, a potência instalada para geração eólica no país expandiu 33\%. Segundo o Banco de Informações da Geração (BIG), da Agência Nacional de Energia Elétrica (ANEEL), o parque eólico nacional cresceu 2.491MW, alcançando 10.124MW ao final de 2016.

Figura 6 - Percentual de Fontes renováveis na Matriz Energética Brasileira

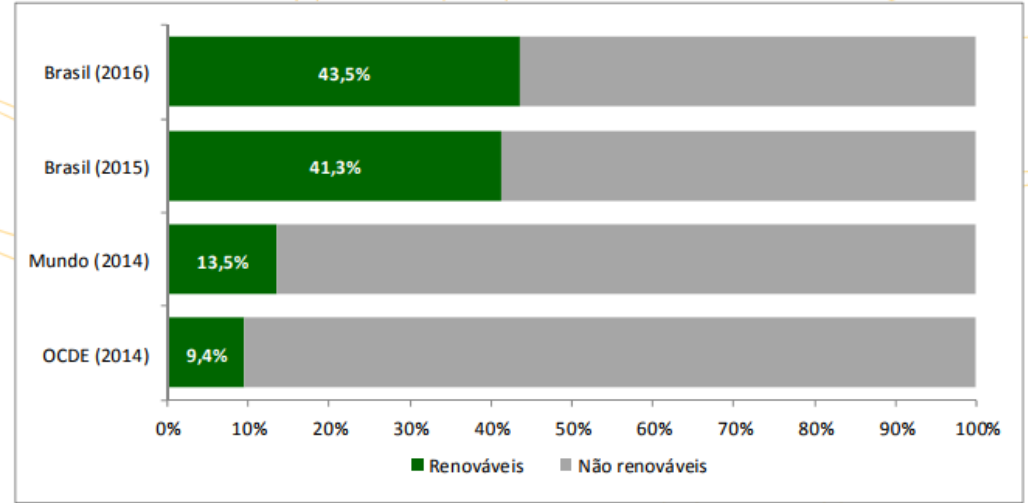

Fonte: EPE, 2017.

Segundo o EPE (2017), a matriz energética brasileira em 2016, teve sua participação de $43,5 \%$, quantidade essa que é muito elevada, comparado ao nível mundial, que em 2014, obteve 13,5\%, conforme Figura 6.

Na participação da matriz energética $5,4 \%$ dos $43,5 \%$ é proveniente da 
lixívia e outras fontes renováveis. A energia proveniente dos ventos ou energia eólica tem ainda uma pequena parcela de participação de $18,4 \%$ dentro dos $5,4 \%$, conforme figura 7.

Figura 7 - Repartição de lixívia e outras renováveis

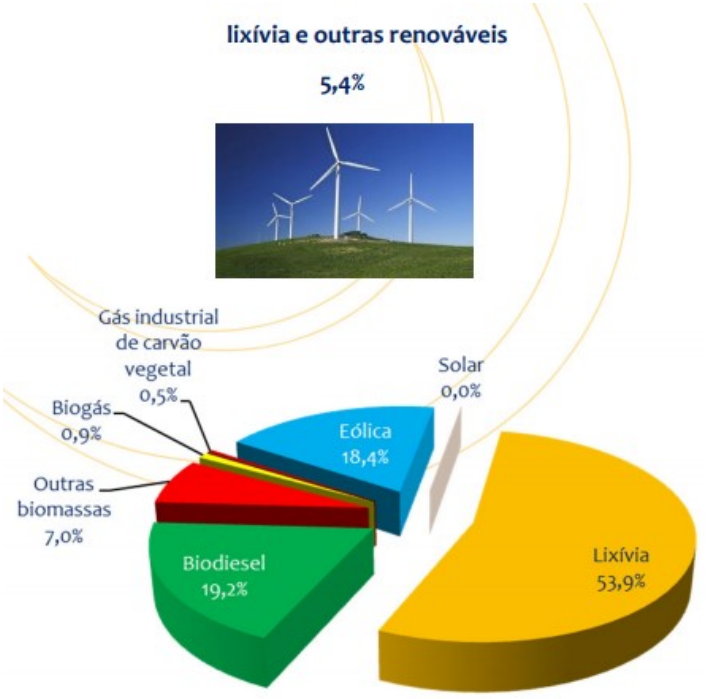

Fonte: EPE, 2017

$\mathrm{Na}$ Tabela 3 e na figura 7, respectivamente, é possível observar a capacidade instalada (MW), o que explicita um grande avanço na capacidade instalada de energia eólica no Brasil, obtendo um crescimento de $32,6 \%$ entre o ano de 2015 e 2016.

Tabela 3 - Capacidade instalada (MW)

\begin{tabular}{|l|r|r|r|}
\hline Fonte & 2015 & 2016 & $\Delta 16 / 15$ \\
\hline Hidrelétrica & 91.650 & 96.925 & $5,8 \%$ \\
\hline Térmica ${ }^{2}$ & 39.580 & 41.276 & $4,3 \%$ \\
\hline Nuclear & 1.990 & 1.990 & $0,0 \%$ \\
\hline Eólica & 7.633 & 10.124 & $32,6 \%$ \\
\hline Solar & 21 & 24 & $13,1 \%$ \\
\hline Capacidade disponível & 140.874 & 150.338 & $6,7 \%$ \\
\hline
\end{tabular}

Fonte: $\mathrm{EPE}, 2017$.

A energia eólica é uma das que mais cresce no Brasil, ressaltando o grande avanço da geração de energia eólica no ano de 2015 e 2016, com um significativo aumento de $54,9 \%$, por conta do vasto litoral, boas correntes de vento, e com isso, é gerada muita energia de forma eficiente e limpa.

Importante ressaltar que a energia gerada pela fonte eólica em 2017 foi capaz de fornecer energia elétrica residencial a uma população maior que a da região nordeste (mais de 57 milhões de pessoas), contribuindo assim com o 
abastecimento residencial.

De acordo com a resenha mensal publicada pela EPE - Empresa de Pesquisa Energética, o consumo médio residencial no Brasil, no ano de 2017, foi de 157 kWh por mês. Na média, foram abastecidas 22,4 milhões de residências por mês, o equivalente a cerca de 67 milhões de habitantes, tendo registrado crescimento de $28,84 \%$ em relação ao ano anterior, quando a energia eólica abasteceu 52 milhões de pessoas (ABEEÓLICA, 2017).

Figura 8 - Evolução da Geração Eólica

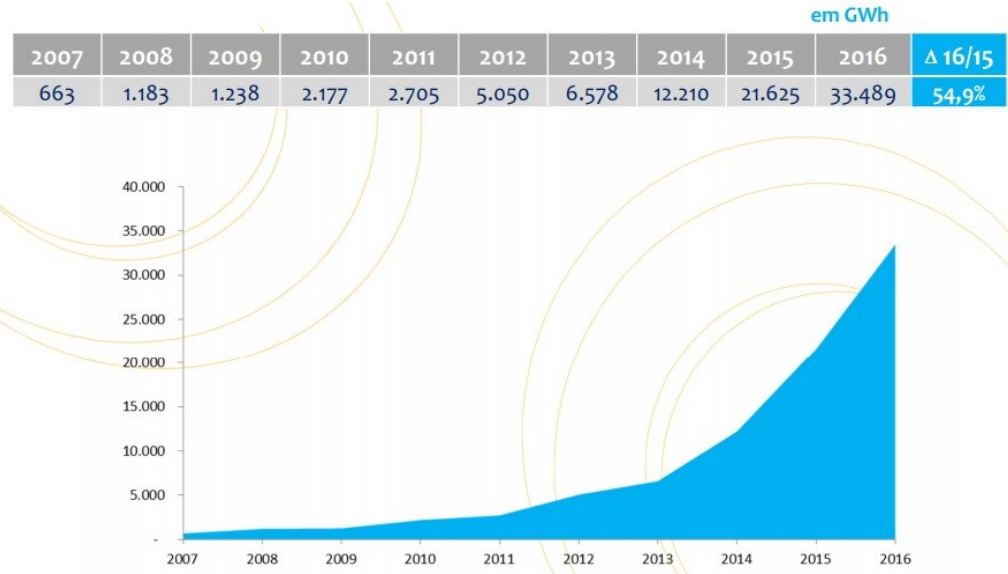

Fonte: EPE, 2017.

Para a obtenção deste tipo de energia elétrica é necessária a construção de parques ou usinas eólicas. Segundo Goldemberg (2016), a construção de parques eólicos inclui a criação de acesso rodoviário, construção civil das bases das torres e da subestação, da fundação, a montagem de cabos de transmissão elétrica e a montagem de torres eólicas e de rotores.

Ao planejar essas etapas, os aspectos do local a ser instalado e o parque eólico, devem ser levados em consideração. Logo, o interesse por este tipo de energia renovável leva consequentemente ao aumento na construção de parques eólicos.

Segundo Lima e Lins (2018), o crescimento da potência instalada de fonte eólica no Nordeste, de 2016 a 2021, será de quase $80 \%$, sendo que esta fonte representará $40 \%$ da matriz energética nordestina.

"Pode-se dizer que atualmente a fonte eólica apresenta-se como a mais competitiva do País. Há um expressivo número de projetos desenvolvidos e em desenvolvimento, além de grande potencial ainda a ser explorado" (LIMP, 2019).

\section{CARACTERIZAÇÃO E DISCUSSÃO DA UNIDADE DE ANÁLISE: PARQUES EÓLICOS LAGOA I E II E CANOAS/ PB}

O Brasil, por suas dimensões continentais, possui regiões geográficas com diferentes características climáticas. Alguns com forte sazonalidade, como sul e sudeste do Brasil, e outros com uniformidade climática anual, como é o caso do nordeste brasileiro (RIBEIRO, ARUCA e COELHO, 2016).

Segundo a CERNE (2018), a cerca de 700 metros acima do nível do mar, em pleno sertão paraibano há uma mina de ouro quase inexplorada, mas que é encontrada na forma de ventos. Mapeamento feito pela Iberdrola, aponta que ali naquela região há um enorme potencial no melhor estilo do polo de João Câmara 
(RN). A região conhecida como Seridó está a cerca de $350 \mathrm{~km}$ de distância da capital João Pessoa em direção ao interior do estado. É composta por montanhas com solo rochoso e escassez de água.

O complexo eólico em análise, foi construído na região serrana, num local conhecido como Cabaço, entre os municípios de Santa Luzia e São José do Sabugi, e abrange também a cidade de Junco do Seridó.

Figura 9 - Regiões com potencial eólico na Paraíba

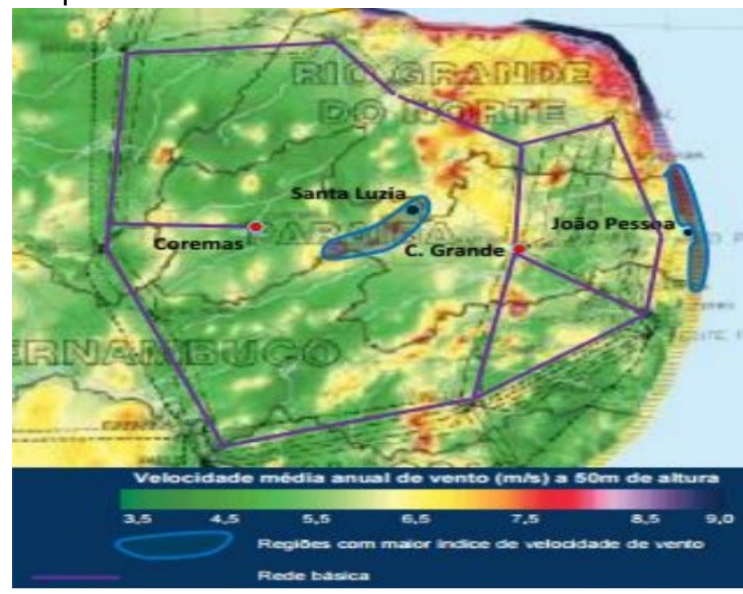

Fonte: NOGUEIRA, 2014.

Os municípios de Santa Luzia, São José do Sabugi e Junco do Seridó estão situados na região do Seridó Ocidental Paraibano. Santa Luzia se encontra em um "corredor" de vento situado no agreste paraibano. Possui velocidade média anual de vento em torno de $7,7 \mathrm{~m} / \mathrm{s}$, situação favorável para implantação de parques eólicos. Porém, essa região encontra-se distante da rede básica dificultando a conexão de usinas à mesma (NOGUEIRA, 2014).

O complexo composto por três parques eólicos, é o primeiro complexo eólico no Sertão Paraibano. Conta com 45 aerogeradores G114 - 2,1 MW em funcionamento desde outubro de 2017 e potência instalada total de 94,5 MW, onde toda a energia gerada será suficiente para abastecer 150 mil residências. (SÁ, 2016). Com 15 aerogeradores por parque, cada um possui uma capacidade instalada de 31,5MVA (IBERDROLA, 2018).

Segundo Iberdrola (2018), o complexo eólico deverá ter uma capacidade instalada total de 471 megawatts (MW), e será formado por 18 parques eólicos.

A Força Eólica do Brasil, joint venture entre os grupos Neoenergia (50\%) e Iberdrola (50\%), foi a vencedora de três empreendimentos de geração de energia no Leilão A-5 (com início de operação em 2019), realizado pela Agência Nacional de Energia Elétrica.

A IBERDROLA é o maior produtor de energias renováveis da Europa e dos EUA, uma das cinco maiores companhias elétricas do mundo e o líder mundial em energia eólica (IBERDROLA, 2018).

\section{METODOLOGIA}

A presente pesquisa caracteriza-se como bibliográfica exploratória, pois, foi realizada diante de análise e debate do tema, tendo como base, materiais bibliográficos, publicações em periódicos, entrevista de jornal, trabalhos acadêmicos, sites disponibilizados, além de relatórios e balanços energéticos atuais. 
O estudo de caso desta pesquisa foi realizado, in loco, no período de construção do Parque Eólico localizado em Santa Luzia - Paraíba. Segundo a Neoenergia (2018), o município de Santa Luzia foi escolhido porque se trata de uma das áreas com maior potencial eólico do continente americano.

Goode e Hatt (1973), afirmam que o estudo de caso pode ser caracterizado como o estudo profundo de um objeto, de maneira a permitir amplo e detalhado conhecimento sobre este, o que seria praticamente inviável através de outros métodos de investigação.

Segundo os autores o estudo de caso caracteriza-se como um meio de organizar dados e reunir informações, tão numerosas e detalhadas quanto possível, a respeito do objeto de estudo de maneira a preservar seu caráter unitário. Importante ressaltar que foi realizada consulta com funcionário responsável pela subestação do parque eólico em estudo, e com gerente de impressa e sustentabilidade da empresa Neoenergia.

Sendo assim, o trabalho discorre à análise do potencial eólico brasileiro voltado à sustentabilidade e o setor da construção civil, balanço energético brasileiro, caracterização do complexo eólico em pesquisa, impactos devido à construção e operação, benefícios ganhos pela região decorrente da construção civil do parque, capacidade gerada, número de habitantes atendidos, entre outros fatores.

\section{RESULTADOS E DISCUSSÕES}

Tratando-se de impactos ambientais, as usinas eólicas são as que produzem menos impactos como já ressaltado anteriormente. Este tipo de fonte é avaliada atualmente como uma das mais auspiciosas fontes naturais e renováveis, devido a sua fonte inesgotável, que é o vento. A produção de energia eólica não causa poluição em sua operação, dessa forma é mirada como uma contribuição de grande valia no que diz respeito à redução de emissão de gases de efeito estufa e na redução da concentração de $\mathrm{CO} 2$.

A área ocupada do terreno no qual são instaladas os aerogeradores, não afeta substancialmente o meio habitado pela comunidade, podendo ser utilizada a área para fins de agricultura (SOUZA, CUNHA e SANTOS, 2013). A utilização de tecnologias sustentáveis, como a aplicação da energia eólica, por comunidades rurais, reflete na possibilidade de redução dos custos de produção relativos ao consumo energético (PARANHOS, SILVA e CATALDI, 2017).

Segundo a ALAGER (2018), o impacto sobre o solo ocorre de forma pontual à área de instalação da base de concreto onde a turbina é instalada. Vários testes de compactação do solo são feitos para avaliação das condições de instalação de cada turbina. Nas Figura 10 e 11, é possível observar respectivamente, a etapa de execução da fundação dos aerogeradores e visão aérea do Parque eólico em estudo, uma das usinas que compõem o complexo eólico na paraíba. 
Figura 10 - Execução da fundação dos aerogeradores

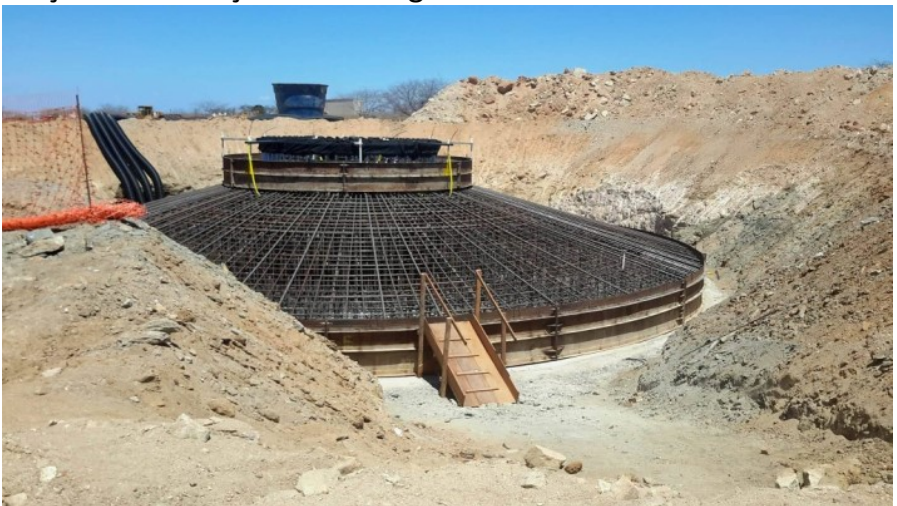

Fonte: CREA, 2018.

Segundo Lobo (2018), a fundação de uma estrutura é o elemento construtivo responsável por transferir os carregamentos estáticos - como peso próprio - bem como os dinâmicos - como o vento e, eventualmente, a ação sísmica - para o solo. No caso da fundação de um aerogerador, esta verdade se mantém, havendo, entretanto, peculiaridades envolvidas relativas ao tipo de estrutura - 0 aerogerador - se diferenciar bastante das estruturas mais comuns na engenharia civil.

Figura 11 - Vista aérea parque eólico em Santa Luzia - PB

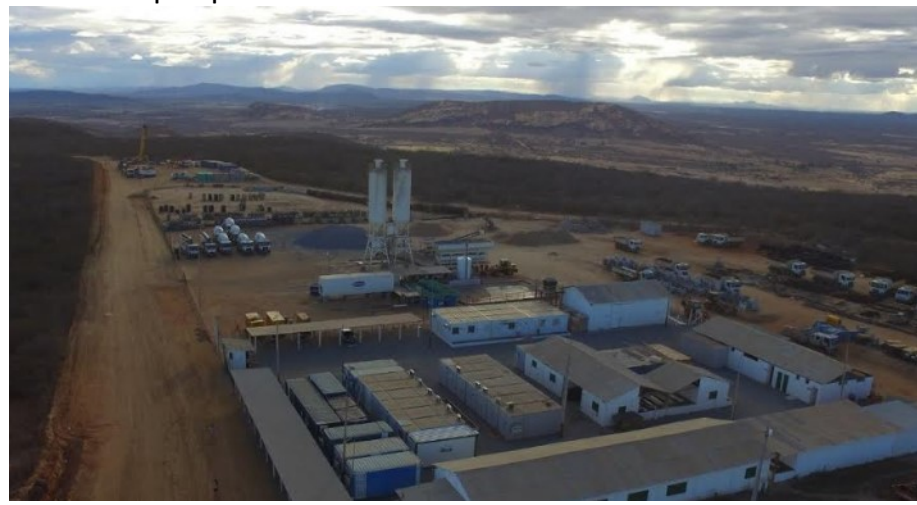

Fonte: CREA, 2018.

As emissões de ruídos causados pelos aerogeradores, pertinente ao funcionamento mecânico e ao efeito aerodinâmico, considerando o atendimento às normas técnicas e legislação do pais sobre decibéis $(\mathrm{dB})$ são irrisórios, não causando desconforto, intolerância ou incômodo as comunidades que residem próximo ao local de instalação dos parques.

Os impactos visuais também podem ser considerados irrisórios, pois foi projetada uma correta planificação do parque para que não houvesse efeito de sombras e reflexões intermitentes. Segundo relatos de moradores das comunidades e cidades circunvizinhas, não foi constatado casos de intolerância devido a esse aspecto. 
Figuras 12 - Aerogeradores eólicos

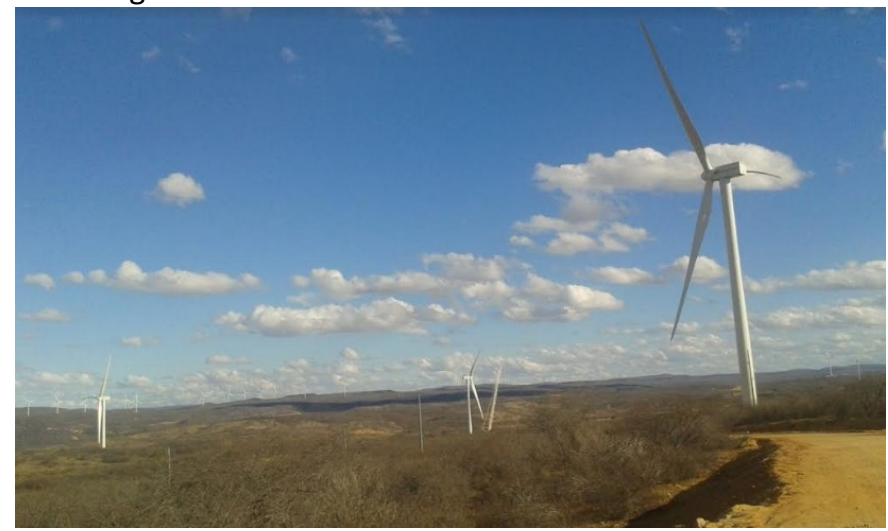

Fonte: Autores (2017)

Figuras 12 - Aerogeradores eólicos

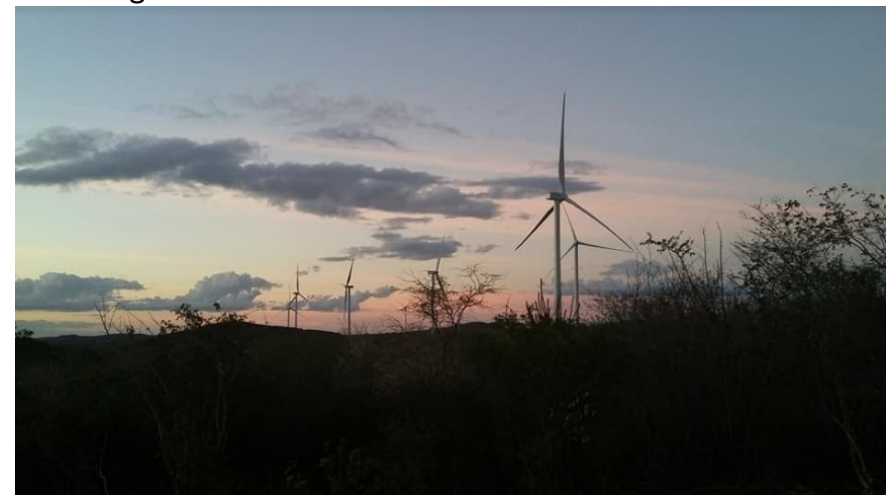

Fonte: Autores (2017)

O complexo eólico conta com uma estimativa calculada pela empresa de capacidade gerada, energia anual estimada, garantia física, $\mathrm{CO} 2$ equivalente não emitido e número de habitantes beneficiados pela produção desta fonte de energia, conforme mostra a tabela 4.

Tabela 4 - Parques implantados e aspectos quantitativos

\begin{tabular}{llllll}
\hline PARQUE & $\begin{array}{l}\text { CAPACIDADE } \\
(\text { MW })\end{array}$ & $\begin{array}{l}\text { ENERGIA } \\
\text { ANUAL } \\
\text { ESTIMADA } \\
\text { (GWH) }\end{array}$ & $\begin{array}{l}\text { GARANTIA } \\
\text { FISICA } \\
\text { (MWM) }\end{array}$ & $\begin{array}{l}\text { CO }{ }^{2} \text { EQUIVALENTE } \\
\text { NÃO EMITIDO } \\
\text { (TCO2/MWH) }\end{array}$ & $\begin{array}{l}\text { No DE } \\
\text { HABITANTES } \\
\text { BENEFICIADOS }\end{array}$ \\
Canoas & 31,5 & 155 & 17,7 & 78.549 & 242 \\
Lagoa 1 & 31,5 & 164 & 18,7 & 82.987 & 256 \\
Lagoa 2 & 31,5 & 153 & 17,5 & 77.662 & 240 \\
\hline
\end{tabular}

Fonte: NEOENERGIA, 2018

Diante o número de habitantes beneficiados na região com o abastecimento dessa fonte, vale ressaltar que esse número está aumentando devido a construção de novos parques na região até 2023, podendo gerar até 2 GW, proveniente da excelente operação do empreendimento já instalado, no qual estão em fase de construção mais de 15 parques, tendo destaque regional, gerando inúmeros postos de emprego verde, assim como na construção das usinas já instaladas, que geraram cerca de 400 postos de emprego no pico da obra, ressaltando que a geração de emprego é um aspecto-chave no 
desenvolvimento econômico de uma região.

Vale salientar também o desenvolvimento tecnológico da região. 0 processo de crescimento neste ramo na região ainda torna-se lento devido a barreira estrutural devido à ausência da linha de transmissão para o escoamento desse potencial.

Analisando a concepção governamental, o complexo dos três parques trouxe benefícios para os municípios de Santa Luzia, São José do Sabugi e Junco do Seridó, muito superiores aos eventuais impactos causados pelos parques. Além dos benefícios de energia, e aqueles promovidos pelas medidas compensatórias, outros fatores positivos são identificáveis. Como exemplo, a valorização das propriedades e terras no entorno dos parques, a divulgação das cidades em todo país e até mesmo no exterior, a visitação turística ao parque eólico e principalmente a geração de novos postos de empregos estimulando o desenvolvimento econômico local e regional (SÁ, 2016).

\section{CONCLUSÃO}

Considerando as informações expostas acima, é possível comprovar os diversos benefícios, ambientais e econômicos, que as inovações no setor de energia eólica brasileiro proporcionam, pois, além de permitir uma redução considerável na quantidade de gases poluentes provindos de fontes não renováveis a base de combustíveis fósseis, por exemplo, também ajuda no abastecimento durante os tempos de estiagem, quando os níveis dos reservatórios das hidrelétricas estão reduzidos comprometendo assim a sua eficiência.

Com o reconhecimento dos grandes empresários e pesquisadores, essa fonte limpa, em conjuntos com as demais fontes renováveis, vem ganhando cada vez mais espaço dentro da matriz energética nacional, no entanto, é importante ressaltar que as políticas setoriais devem buscar um meio para proporcionar um crescimento mais acelerado para produção de energia eólica, visando utilizar ao máximo a capacidade que o país pode chegar a produzir futuramente.

Essas políticas também devem servir como apoio para a realização de mais estudos e pesquisas com o intuito de continuar buscando desenvolver novas tecnologias, regradas por padrões elevados de qualidade que estimulem a competição e com isso o barateamento do custo da energia produzida no país. Em termos estratégicos, a ampliação do número de parques eólicos, principalmente no Nordeste Brasileiro, possibilitará a complementaridade eólico-hídrica colaborando para aumento da segurança energética do sistema elétrico brasileiro nos períodos do ano de maior e menor disponibilidade de água nos reservatórios das usinas hidroelétricas. 


\title{
Analysis of Brazilian wind potential: in loco case study of wind farm construction in Santa Luzia - PB
}

\begin{abstract}
Finding clean and inexhaustible sources of energy is becoming more and more common and necessary. Brazil was a pioneer among the countries of Latin America, during the 90's, joining the wind energy technology when installing the first wind turbine. With the advancement of this technology and the excellent conditions found by researchers and investors, especially in the Northeast, the creation of wind farms has grown considerably over the years, with the potential to grow more and more, enhancing the construction sector. The objective of this article was to analyze the Brazilian wind potential, addressing relevant aspects, social, environmental and economic contributions, advantages of this type of production for the region, having the experience in loco, in the analysis of the construction of a wind farm located in Santa Luzia - PB. The study city is renowned for its high winds and is known as the "wind corridor". The research is characterized as bibliographic, exploratory and documentary, having the case study as methodology. There are several benefits in the use of this type of energy, environmental, social and economic, and that innovations in the Brazilian wind energy sector, mainly in the Brazilian Northeast, provide the wind-water complementarity collaborating to increase the energy security of the system in the periods of the year of greater and lesser availability of water in the reservoirs of hydroelectric power plants.
\end{abstract}

PALAVRAS-CHAVE: Wind energy. Santa Luzia Wind Farm. Construction of wind farms. Renewable energy. 


\section{REFERÊNCIAS}

ABEEÓLICA. Associação Brasileira de Energia Eólica (Brasil). Boletim Anual de Geração Eólica 2017. Disponível em: < http://abeeolica.org.br/wpcontent/uploads/2018/04/Boletim-Anual-de-Geracao-2017.pdf > . Acesso em: 19 de setembro de 2018.

ABEEÓLICA. Associação Brasileira de Energia Eólica (Brasil). Números ABEEólica. Disponível em: < http://almaco.org.br/wp-content/uploads/2018/02/DadosMensais-ABEE\%C3\%B3lica-Janeiro-de-2018.pdf> Acesso em : 22 de dezembro de 2018.

ALAGER, Associação Latina Americana de Geração de Energia Renovável. Energia Eólica. Disponível em: <http://alager.org.br/energia_eolica.html> Acesso em: 22 de setembro de 2018.

ANEEL, Agência Nacional de Energia Elétrica. Geração Distribuída. Disponível em: <http://www.aneel.gov.br> Acesso em : 20 de Janeiro de 2019.

BORBA, F. W. da S. Análise/estudo do uso de energia solar fotovoltaica no setor da construção civil: Estudo de caso de uma aplicação On Grid. Monografia. Graduação em Engenharia Civil - Centro Universitário de João Pessoa (UNIPÊ), 2018.

CBIC, Câmara Brasileira da indústria da construção. Energia nas construções, Brasília, maio de 2017.

CERNE. Centro de Estudos de Energias Renováveis. Indicadores Eólicos. Disponível em: <http://cerne.org.br/potencial-mapeado-de-geracao-eolica-no-interior-daparaiba-chega-a-2-gw/> Acesso em: 25 de setembro de 2018.

CREA, Conselho Regional de Engenharia e Agronomia da Paraíba. CREA fiscaliza parques eólicos. Disponível em: <https://creapb.org.br/noticias/crea-pb-fiscalizaparques-eolicos-no-interior-da-paraiba/> Acesso em: 26 de setembro de 2018.

EPE (Brasil). BEN. Balanço Energético Nacional 2017: Ano base 2016 / Empresa de Pesquisa Energética. - Rio de Janeiro : EPE, 2017.

GOODE, W.; HATT, P. Métodos em pesquisa social. São Paulo, SP: Nacional, 1973.

GREENPEACE. Revolução energética: a caminho do desenvolvimento limpo. Cenário Brasileiro. 2013.

GOLDEMBERG, J. Potencial eólico no Brasil pode ser maior do que o estimado. Jornal USP, São Paulo,14 nov. 2016. Disponível em:

$<$ https://jornal.usp.br/atualidades/potencial-eolico-no-brasil-pode-ser-maior-doque-o-estimado/> . Acesso em: 30 de agosto de 2018.

IBERDROLA. Energética do Futuro. Disponível em : < https://www.iberdrola.com/quem-somos/energetica-do-futuro> Acesso em : 20 de setembro de 2018. 
LIMA, M. C. A. ; LINS, F. G. Principais desafios, impactos e características da geração eólica na região nordeste do Brasil. Cenários Eólica. Disponível em : <https://cenarioseolica.editorabrasilenergia.com.br/2018/12/04/principaisdesafios-impactos-e-caracteristicas-da-geracao-eolica-na-regiao-nordeste-dobrasil/> Acesso em : 22 de dezembro de 2018.

LIMP, R. Por que os preços da energia eólica estão caindo e como podem chegar ao consumidor no Brasil? Cenários Eólica. Disponível em : $<$ In:https://cenarioseolica.editorabrasilenergia.com.br/2019/01/14/por-que-osprecos-da-energia-eolica-estao-caindo-e-como-podem-chegar-ao-consumidor-nobrasil/> Acesso em : 09 de janeiro de 2019.

LOBO, J. R. Estudo do projeto geotécnico de fundação de uma turbina eólica / Projeto de Graduação - UFRJ / Escola Politécnica / Curso de Engenharia Civil, 2018. Júlia Ramos Lôbo. - Rio de Janeiro: UFRJ / Escola Politécnica, 2018.

MME, Ministério de Minas e Energia. Energia Eólica Offshore. Disponível em: $<$ http://www.mme.gov.br/> Acesso em : 06 de outubro de 2018.

NEOENERGIA. Energia Eólica. Disponível em: <http://www.neoenergia.com/Pages/LINHAS\%20DE\%20NEG\%C3\%93CIOS/comple xo-santa-luzia.aspx.> Acesso em : Janeiro de 2019.

NOGUEIRA, F. Eixos Integrados de desenvolvimento da Paraíba: uma visão estratégica para o Estado, João Pessoa, 2014. Disponível em: < http://www.paraiba.pb.gov.br/downloads/eixos_integrados/modulo_energia.pdf > Acesso em: 25 de Setembro de 2018.

PARANHOS, B. R. ; SILVA, F. C. da ; CATALDI, M.. A energia eólica como alternativa energética para agricultura familiar em regiões serranas. Ciência e Natura, Santa Maria. Revista do Centro de Ciências Naturais e Exatas - UFSM, v.39 n.1, p. 193 201, 2017. crossref

RIBEIRO, A. E. D.. AROUCA, M. C. ; COELHO, D. M. Electric energy generation from small-scale solar and wind power in Brazil: The influence of location, area and shape. Renewable Energy , v. 85, p. $554-563$, 2016. crossref

SÁ, S. de. Energia limpa: Paraíba terá três Parques Eólicos até 2017. FIEP, Campina Grande, 19 ago. 2016. Disponível em: <http://www.fiepb.com.br/noticias/2016/08/19/energia_limpa_paraiba_tera_tre s_parques_eolicos_ate_2017>. Acesso em: 20 de setembro de 2018.

SEBRAE, Serviço Brasileiro de Apoio às Micro e Pequenas. Desenvolvimento Sustentável. Disponível em :< https://www.sebrae.com.br/sites/PortalSebrae/Busca?q=\%20desenvolvimento\%2 0sustent\%C3\%A1vel> Acesso em : 20 de setembro de 2018.

SIMAS, M.; PACCA, S. Energia eólica, geração de empregos e desenvolvimento sustentável. Estudos Avançados, v.27, n.77, p.99-116, 2013. crossref 
SCHOLTEN, D.; BOSAMAN, R.; A geopolítica das energias renováveis: uma mera mudança ou desmoronamento nas dependências energéticas? Disponível em: <https://repository.tudelft.nl/islandora/object/uuid:97c5bfda-7d04-4baf-bdddfa7309acdc71?collection=research >, 2013. Acesso em: 28 de agosto de 2018.

SOUZA, L. L. de ; CUNHA, R. B. da ; SANTOS, M. H. P. Análise da Geração de Energia Eólica. Semana Acadêmica UNIBH - Centro Universitário de Belo Horizonte, 2013.

SOUZA, D.T. et al;. Análise Do Potencial Eólico Brasileiro: Estudo De Caso In Loco Da Construção Do Parque Eólico Em Santa Luzia - PB. Revista Gestão. Industrial., Ponta Grossa, v. 16, n. 2, p. 124-141, Abr./Jun. 2020. Disponível em: https://periodicos.utfpr.edu.br/revistagi Correspondência:

Adriana de Souza Nascimento

Rua Golfo de Tailândia, número 55, Apt. 301. Edf. Aloysio Machado. Bairro Intermares, Cabedelo, Paraíba, Brasil. Cep: 58102.092

Direito autoral: Este artigo está licenciado sob os termos da Licença Creative Commons-Atribuição 4.0 Internacional.

$$
\text { (c) (1) }
$$

